Journal of Social Sciences 6 (3): 429-438, 2010

ISSN 1549-3652

(C) 2010 Science Publications

\title{
A Review Study on Spiritual Intelligence, Adolescence and Spiritual Intelligence, Factors that may Contribute to Individual Differences in Spiritual Intelligence and the Related Theories
}

\author{
Maryam Hosseini, Habibah Elias, Steven Eric Krauss and Siti Aishah \\ Faculty of Educational Studies, University Putra Malaysia, Malaysia
}

\begin{abstract}
Problem statement: This study reviewed the articles about adolescence, its relation to spiritual intelligence and the related theories. The adolescence period is the best time to develop positive emotions and training skills, because adolescents are seeking to find their identity and their future personality at this period. Approach: Spiritual intelligence had a significant influence on the quality of life and it goes without saying that adolescence is a sensitive period which requires specific training to make a brighter future and be exposed to the difficulties. Spirituality can be viewed as a form of intelligence because it predicts functioning and adaptation and offers capabilities that enable people to solve problems and attain goals. Results: Conceiving spirituality as a sort of intelligence extended the psychologist's conception of spirituality and allowed its association with the rational cognitive processes like goal achievement and problem solving. Conclusion: Emotional intelligence allowed us to judge in which situation we were involved and then to behave appropriately within it. Spiritual intelligence allowed us to ask if we want to be in this particular situation in the first place.
\end{abstract}

Key words: Spiritual intelligence, adolescence, Erikson's theory

\section{INTRODUCTION}

Research has proposed that spiritual beliefs, practices and commitments seem to be linked with positive results like psychological, psychological and physical health; marital satisfaction and stability; positive interpersonal performance and improved quality of life (Seybold and Hill, 2001). One of the factors that contribute to these positive results may be that possessing spiritual orientation about life protects humans against non-desirable and non-adaptive behaviors like acting in destructive ways, socially or even personally (Emmons, 2000a). Edwards (2003) has pinpointed to differentiation between use of spiritual intelligence or sources to resolve spiritual dilemma and employing them in solving non-spiritual problems. Absolutely, spiritual intelligence is not simply integrating one's intelligence with his/her spirituality. On the contrary, it represents a combination of the individual's personality characteristics, neurological processes, specialized cognitive capabilities and spiritual qualities and interests. It can help us to outgrow our immediate ego selves and to reach beyond those deeper layers of potentiality that lie hidden within us. It helps us to live life at a deeper level of meaning. And finally, we can use our SQ to wrestle with problems of good and evil, problems of life and death, the deepest origins of human suffering and often despair. Too often, we try to rationalize such problems a way, or else we become emotionally swamped or devastated by them (Zohar and Marshall, 2000b). A number of the spiritual intelligence qualities and capabilities, like integrity, self-awareness, creativereasoning, wisdom, self-awareness, and raising the question 'why' (Sisk and Torrance, 2001), can be claimed to suit a much wider range of issues and troubles apart from spiritual or being matters (Emmons, 2000b). For instance, these may be applied to concept formulation and to solution of problems related to relationships. They may, in addition, be employed in the work context for the purposes of establishing institution policies, missions statements and for planning.

Adolescence and spiritual intelligence: Adolescence is the period in which the foundation for future education, major life roles, relationships and working toward long-term productive goals are established. Similarly, adolescence is an important period for the development of preventive interventions which are designed to lead to the development of more serious psychopathology in adulthood. Adolescence as a formative stage plays a significant role in the study of developmental psychopathology because after this 
maturational interval, it is difficult to change some behavioral and emotional patterns. Due to the rationales which are not realized yet, seemingly, there is a consolidation of psychopathology in adolescence which is often carried over into adulthood. As it is suggested by prospective longitudinal studies the majority of chronic and recurrent psychiatric problems faced by adults usually start by the end of adolescence period. In fact, the primary symptoms of affective disturbance, antisocial behavior and substance abuse seem to be very much less frequent in adulthood rather than in the childhood periods and usually appear before the problems in these or other aspects during adolescence. This applies both to problems with behavior, as in the disruptive behavior disorders, as well as to problems with emotion regulation, as in the mood and anxiety disorders (Moffitt et al., 2001). Adolescence also plays a significant role for setting lifestyle milestones with various long-term implications for adult health.

In general, adolescence can be defined as a period of high risk. Anyway, some people are likely to be at greater risk than the others. Children who are believed to be at the greatest risk may include those children who start this difficult transition while they are already sensitive as well as the children who become sensitive during this challenging time (because of genetic tendencies and/or previous serious experiences), those children for whom the separation between developmental aspects are the most, those who face the most challenges during the transition, those who may have the least social support and those children who suffer from bad combinations of low resources and very much genetic and/or developmentally gained sensitivity. One of the greatest objectives of studies on psychopathology in adolescence is to gain a more thorough comprehension of the processes -and mechanisms-by which behavior, neurobiology and context interact during this transition to cause sensitivity and risk that for some individuals can spiral into remarkable long-term impairments and psychopathology.

For many years, the study of psychological malfunctioning and the study of adolescent development have been extremely integrated both empirically and conceptually. For a long time, many people including scientists, Philosophers, clinicians, and literally all observers of human behavior have noticed that adolescence is a period which is specially significant for the occurrence or intensification of different forms of behavioral and emotional disorders like many internalizing problems (depression, bipolar illness, eating disorders), externalizing problems (delinquency, violence) and addictive disorders (alcohol abuse and dependency, drug abuse and dependency). Though there is disagreement among the scholars on the importance of adolescence in the study of clinical phenomena, there is little argument over its own importance. In fact, the list of clinical phenomena not being somehow basically associated with adolescence is possibly shorter than the list of clinical phenomena which are related to adolescence. Anyway, there is still argument with regard to the reality of these developmental tendencies. On the one hand, certain changes in the breakout of clinically meaningful behavioral and emotional problems which clearly happen during adolescence; On the other hand, most of adolescents pass through this developmental period with only slight or mild symptoms of impairment resulting from psychopathology.

Four observations surface repeatedly in discussions of the development of psychopathology in adolescence (Masten, 1988; Morison and Masten, 1991). First, there is a notable increase in the prevalence of certain types of psychopathology during adolescence, including depression, social anxiety, eating disorders, psychosis and substance abuse and dependence. Such data support the notion that early adolescence is a period of heightened vulnerability for affective and behavioral disorder. In each case, these changes in prevalence appear relatively dramatic (Costello et al., 2002).

Second, there are significant changes in the emergence of various forms of psychopathology during adolescence. For instance, the cognitive signs of depression, such as hopelessness, become more notable characteristics of emotional disturbance as people become more able of hypothetical and abstract thinking. Actually, it is believed that maturation in cognitive processes in early adolescence creates a new state of vulnerability in some people. The combination of adverse life experiences with this underlying cognitive diathesis that becomes manifest during adolescence is thought to account for adolescent increases in rates of MDD (Hankin and Abramson, 2001). Similarly, the outward manifestations of conduct problems become more serious, as antisocial behavior becomes more connected with criminal activity. Notably, relatively few studies examine the way in which symptom profiles are transformed between childhood and adolescence and between adolescence and adulthood (Avenevoli and Steinberg, 2001). And finally, some but not all forms of psychopathology in adolescence have indicated significant changes in breakout during historical time; in general, the breakout has increased for frequent generations.

Hence, while the process of movement from childhood to adulthood has possibly always been 
accompanied with dangers for human development, present situations of adolescent development have increased the risk for special problems which may be observed in patterns of risk-taking behaviors, affective disturbance, eating disorders and substance abuse. Considerable complications are recognized to arise in the attempts to test changes in breakout of adolescent mental disorders during time. Certain reductions in stigma accompanied with mental sickness and progress in methods for measuring the amount of psychiatric disorders during time, the sensitivity for discovering disorders may change across continuous intervals of adolescence. Anyway, the statistics on completed suicide seem to be less sensitive to these effects than the figures on special situations, like main depressive disorder. Data documenting increases during adolescence in rates both of completed suicide and major depression during the last half of the 20th century suggest that rates of psychopathology among adolescents have genuinely increased (Costello et al., 2002). These historical changes imply that, in spite of the vital significance of biological change as a defining feature of adolescence and a potential contributor to psychopathology, contextual factors are proved to be very important in the development of behavioral and emotional problems within this period.

In childhood we are taken care of by our parents, but in adolescence, we are required to develop our own mind and at times find this extremely hard with our education which is IQ biased. The major duty of the character is to keep us in the change from childhood to adolescence and future adulthood and now it is much easier to realize why the characteristics stated prior to EQ developments are so necessary:

- Being able to motivate ourselves and persist in the face of frustrations

- Being able to control our impulses and delay gratification

- $\quad$ Being able to regulate and monitor our moods and keep distress from swamping our ability to think

- Possessing the skill of empathy and ability to hope for better things

All of these phases for forming values and all inform our deeper core and this will be journey of exploration and search. They provide us with the opportunity to successfully move from childhood to adulthood by discovering what we may become.

It goes without saying that this phase can be radical or even shocking changes in case we could pass it we would ask "why are we here? Who sent us here? What is right and what is wrong?"
In adolescence period, we may be made to wonder "why" we should not explain away life but we have to reunite the domains of intelligence from which we have become separated. It is the novelty of the evolutionary process in which humans have to involve by their own choice and desire, when certainty is removed. Unluckily, modern education and the common IQ bias make us ignore the power of decision making and take a role or status in society before having discovered our great capabilities. A wrong certainty is given to us that if we pursue the system, all will go fine. As we know, the crises that so many people face in later life are the undoing of this assumed certainty (Bowell, 2005). Then supplementary programs are needed to cover this weak point. Such programs include: Life skills training, emotional intelligence training and spiritual intelligence training and so on.

SQ allows the intrapersonal and the interpersonal emotions to fill the gap between self and the other. Goleman (1995) wrote about interpersonal, or within the-self, emotions and interpersonal emotions- those we share with others or use to relate to others. However, EQ alone cannot help us bridge the gap. It needs SQ to have knowledge about what we are and what things mean to us and how things give others and their meanings a place in our own world.

SQ is applied to help us to reach more thoroughly towards the very developed people the potential of who we have to be. Each of us forms an identity through a combination of experience and vision, as well as the tension between what we really do and the larger better things which we may do. On the level of pure ago, we are selfish, I centered, materially ambitious and so on. Yet, we surely have transpersonal visions of goodness, beauty, perfection, generosity, sacrifice and so on. SQ helps us develop our immediate ego selves and get beyond those deeper layers of capability which lie hidden within us. It provides us with the opportunity to live a life which has a deeper level of meaning. And eventually, we may apply our SQ to deal with problems of life and death, problems of good and evil as well as the prime roots of human suffering and at times despair. We usually attempt to rationalize such problems and run away from them; otherwise we will be emotionally conquered or despaired by them. To come in to full possession of our spiritual intelligence we have at some time to have seen the face of hell, to have known the possibility of despair, pain deep suffering and loss and to have made our peace with these (Zohar and Marshall, 2000b). Obviously, spiritual intelligence has a significant influence on the quality of life and it goes without saying that adolescence is a sensitive period which requires specific training to make a brighter future and be exposed to the difficulties. 


\section{J. Social Sci., 6 (3): 429-438, 2010}

Theories related to spiritual intelligence: A theorist named Erikson (1902-1994) was oriented psychoanalytically whose assessment about adolescence has been rooted from his examination on adolescents who were disturbed emotionally during the course of treatment. Influential ideals of Erickson have encouraged permit a complete effect on adolescents mainly who were uncertain and anxious regarding themselves and their future as well. Identity diffusion has been naturally encountered by adolescents comprising a resilient nature of ambiguity as claimed by Erikson $(1950 ; 1968 ; 1969)$. There is an essentiality in attaining a true sense of identity that can be described as "a feeling of being at home in one's body, an impression of "awareness in one's direction" and "an inner certainty of predicted recognition from those who reckon" (Erikson, 1950). Given that adolescents were able to endure speedy changes in biological and social aspects, they realized it to be complicated to do this, moreover, they are also obliged to formulate major decisions in entirely all aspects of life. It has been claimed by Erikson (1950) that conventional adolescents consider themselves in certain ways such as "“I ain't what I ought to be, I ain't what I'm gonna be, but I ain't what I was" and were embracing identity crisis because they were unaware of life's direction. What has been involved in such crisis in identity were brought out in a detailed way by Erikson (1969). Adolescence is an ordinary predicament and not an agony which demonstrated a common stage embracing an intensified conflict.

A source of neurosis is frequently an assertive crisis which substantiated to be self-liquidating and added to the formative process of human identity disclosed by biased investigation. Therefore, it is essential for adolescents as clearly claimed by Erikson (1959) to undergo an identity crisis as so as to identify certain resolution for such identity issues that lead to the stability of an adult identity development.

Spiritual intelligence involves an array of capabilities derived from spiritual resources in line with the advancement of an emotional intelligence construct. Constructs of spirituality and intelligence are merged by SI in shaping a new construct. Outrival and superior awareness gave an implication that spirituality stands in the exploration of and live through the holy elements. In forecasting performance, customary adjustment and generation of beneficial products or findings, spiritual intelligence brings out the power drawn on certain spiritual matters (Emmons, 2003).

Spirituality is regarded as a manner of intelligence based from Emmons (2000a; 2000b) depicted on Gardner's definition of intelligence. In other words, spirituality is based on abilities that produce valuable outcomes. In other words, spirituality is rooted on the power in bringing out indispensable outcomes. A research recommendation is regarding the association among spirituality, life's direction, contentment, health and relief (George et al., 2000; Kass et al., 1991; Veach and Chappel, 1992). It has been discovered that the influence of spirituality on health according to the research reviewed by Elmer et al. (2003) plays a role in decreasing disease rate and longer life. Those individuals who were spiritually oriented appear to exceedingly take actions about intervention, positively deal with trauma (Emmons, 2000a) and have reduced rates on depression (Elmer et al., 2003; MacDonald and Holland, 2003). There is a an indication from Trott (1996) study of 184 workers in a Fortune 100 company that spiritual wellbeing and overall self-worth have positive correlations.

A structure in recognizing and managing proficiency and power essential for the customary use of spirituality bestowed the meaning of spiritual intelligence being marked by Emmons (2003) in understanding spirituality through intelligence mechanism. There are five components for SI as suggested by Emmons (2000a) such as: (a) capacity in employing spiritual resources in resolving problems; (b) power to penetrate heightened states of awareness; (c) ability to devote daily undertakings and relationships with sacred implication; (d) competence for physical and material stand out and (e) capability in becoming righteous. Nevertheless, Mayer (2000) claims that virtuous actions preferably belong to character and moral principles than intelligence. In response to such Mayer (2000) criticisms, Emmons (2000b) let go of the fifth component from his modified meaning of SI and keeps hold the primary four components of his model in order to respond to the views of Mayer.

Vaughan (2002) proposed a bit different structure who characterizes that SI is a power to a profound understanding of existing questions and perception about various awareness levels. Its implication stands for the awareness of individual relationship, to the earth and all life forms. For this reason, Vaughan (2002) model is identified in the involvement of the $3 \mathrm{SI}$ components: (a) power to form a meaning that is rooted on a profound knowledge of existential questions; (b) responsiveness in the utilization of multiple consciousness levels aimed to properly address the problems; (c) attentiveness regarding the interconnection of each individual as well as to the transcendent. Zohar and Marshall (2000a) have defined the SI as intelligence in handling and answering, problems of meaning and value. It has also been 


\section{J. Social Sci., 6 (3): 429-438, 2010}

referred to as an intelligence in which people can survive and take actions in a broader, richer, meaningful context. In addition, SI is the intelligence in assessing a course of action or single life-pattern in a meaningful way. The definition of Zohar and Marshall (2000a) gives emphasis and suggestion in relevance to SI as to its association to a greater extent.

Levin (1997) claims that SI is clearly demonstrated when someone lives in a manner of integrating spirituality in his daily activities that extended beyond the views of prior authors. SI advancement requires the ability in utilizing the perceptual powers away from the five senses engaging one's perception together with the recognition of people's interconnection to all issues of life that is viewed as another consciousness and intelligence level far from the logical, linear and realistic thoughts. The human power in soliciting vital questions regarding life's meaning and concurrently in contact with the perfect connection between people and the world they live entails the definition of spiritual intelligence by Wolman (2001). Psycho-Matrix Spirituality Inventory (PSI) of Wolman (2001) looks like more a scale of spiritual tendency rather than spiritual intelligence even though his book is entitled as Thinking with your soul: Spiritual intelligence and why it matters. The PSI has a stable 7-factor structure and has been distributed to more than 6,000 people and regarded as an 80-item self report scale on a 4-point Likert-type scale. However, various PSI items are deficient on face validity in relation to spiritual intelligence. Furthermore, it upholds factors in the assessment of childhood trauma (e.g., personal serious physical injury or loved one's serious illness) and childhood spirituality (e.g., praying habit during childhood). However, such factors do not appear to correspond into Wolman (2001) views or other definitions of spiritual intelligence. Wolman (2001) does not impart any analytical or differentiated validity in carrying out PSI.

Spiritual intelligence as defined by Nasel (2004) is the capacity in bringing out one's spiritual gifts and resources for further recognition, search for meaning and the resolution to certain existential, spiritual and practical matters. These resources and potentialities, be it a prayer, intuition or transcendence must be correlated in simplifying the abilities to seek for meaning of one's existence, facilitation of solving issues and the improving tlone's power for adaptive decision making. Spiritual Intelligence Scale (SIS) is defined by Nasel (2004) as an integral part of a doctoral dissertation. The questionnaire contains items that are all positively worded and intended to behavioral evaluation (e.g., even during desperate situation, one can search for deeper meaning in it or has able to direct ideas obtained from self realization to challenging life's circumstances) and attitudes (e.g., one has positioned his daily undertakings within a broader meaning) rather than plain convictions.

The SIS has been improved in the measurement of spiritual intelligence arising from exclusive set of two attitudes which are individualistic (New Age) spirituality and the traditional Christianity, regardless of the overall satisfactory dependability, construct validity and several restricted analytical validity. Furthermore, having only 17 items, various SI elements that are significant were been excluded from the model of spiritual intelligence applied by SIS. The SIS rules out some items in the evaluation of potentiality pertaining to certain consciousness conditions such as meditation, prayer or sense of solving problems. It does not include factors that correspond to the power of observing the world and completely resolving the crisis. Walsh (2000) recognizes and talks about the general practices that are universal across such spiritual practices in reference to his study of various world's major spiritual traditions (Buddhism, Christianity, Confucianism, Islam, Judaism, Shamanism and Taoism).

Amram (2007) was the first author in developing the ecumenical grounded SI theory originated from the interviews conducted among 71 people of different traditions regarded as spiritually intelligent by their associates. About four interviews were conducted within the individual following spiritual traditions such as Buddhism, Christianity, Earth-Based (Shamanic and Pagan), Hindu, Islam/Sufism, Jewish, Non-Dual, Taoism and Yoga. To add up the well defined traditions, the largest single group of subjects (20) is regarded as eclectic in their spiritual orientation that is consistent with their own distinct personal pattern of several traditions. Thirteen initial themes were acknowledged according to the 45 primary interviews with the subjects. The writers of this study have employed such primary themes in generating various items advanced in this research. Amram (2007) has improved gathered and expanded the themes into 7 major themes as the interviews continued appearing as somewhat universal in the pursuit of spiritual traditions and participants:

- Consciousness: Growth of advanced awareness and self-knowledge that brings out innate trans- logical knowing, attentiveness and spiritual practices

- Grace: To live in accordance with the sacred with the manifestation of trust and love about life that is rooted from happiness, beauty and gratefulness 
- Meaning: Encountering the importance of everyday endeavor through a sense of purpose and a need for service embracing the presence of pain and suffering

- Transcendence: Running away from self-worth into interrelated wholeness covering a holistic system's standpoint and fostering the human relationships by understanding, sympathy and I-Thou orientation

- Truth: To live in open acceptance, forgiveness, interest and love for the creation in reverence of the wisdom of various spiritual practices

- Peaceful surrender: Peacefully submitting to higher-self (God, Truth, Absolute, or true nature) that includes self-completeness, self-acceptance, calmness, humbleness and egolessness

- Inner-Directedness: An innate free will in line with accountable and sensible actions involving judgment, truthfulness and freedom from attachments, conditioning and anxiousness

Various themes generated from qualitative interviews by Amram (2007) were enhanced, validated and further obtained additional confirmation within the Integrated Spiritual Intelligence Scale. Some overlap relative to other meanings and models of SI were been previously reviewed.

A new dimension of human intelligence has been presented by Zohar and Marshall (2000b) and Ian Marshall and linked the term "SQ" that stands for Spiritual Intelligence. SQ becomes the fundamental basis of effective usage of EQ and IQ as being argued by people. It is also been denoted by people as the intelligence of the soul. One's IQ comes from the reasonable and logical thinking while EQ derives from the associated habit-bound and pattern awareness emotional thinking. A person's creativeness, understanding, rule-formulating skill and rule breaking thinking reframe and alter our previous thinking that further provides a person the SQ. SQ permits an individual to include a greater, profound and more affluent context to the present just like the whole can be greater than the sum of its parts. There is no such essential connection with organized religion as to the term "spiritual" relative to intelligence. A person may not have religious faith or belief of any kind even he has a high sense of SQ. In the same way, person with low in SQ could be very religious. A Latin word spirit denotes "that which gives life or vitality to a system" where the word spiritual from Zohar and Marshal (2000a) concept originated.

According to Zohar and Marshall (2000b), Spiritual Intelligence means as:
- Self-Awareness: Knowing oneself and one's connection with the entire universe

- Vision and Values Led-or Idealism. Children logically desire to serve as well as the adults. Humanity is defined by one's vision and values

- The Capacity to Face and use Adversity: Mistakes and adversity are to be admitted. Learning is gained through pains and misfortune

- To be Holistic: Perceiving the relevance of things. It upholds awareness and openness in everything

- Diversity: To succeed in embracing hardships. Ability in seeing and appreciating gifts of oneself from others

- $\quad$ Field Independence (Courage): A psychology term that signifies bravery to adjust and to be self-reliant

- The Tendency to Ask why? Questions are boundless. In Quantum Physics, questions generate reality

- The Ability to Re-Frame: Setting things in a considerable sense of perspective

- Spontaneity: It is rooted from a Latin terminology as response and reliability. It is suitably "sympathetic" to the environment and unaccustomed by fear

Factors contributing to spiritual intelligence individual differences: Much like any other area of human knowledge, the degrees of development and complexity of abilities and spiritual cognition differ remarkably amongst people. Spiritual intelligence is demonstrated in a variety of ways and to varying degrees all through humanity (Noble, 2000). It is reasonable that individuals will differ on the basis of their potentials and tendencies, in how much professional they are in manipulating, using and intercommunicating spirituality-related information. Some people are, from the spiritual development point of view, regarded as highly developed, like Mahatma Gandhi, Mother Teresa and Nelson Mandela, whereas many others demonstrate no spiritual interests. Additionally, a relationship between personality processes and intelligence seems to exist (Emmons, 2000b).

There also appears to be a relationship between intelligence and personality processes (Emmons, 2000b). It is hence possible that characteristics of the personality are associated with personal differences in organizing and expressing spiritual intelligence (Emmons, 2000a; Wolman, 2001). In line with this, MacHovec (2002) has proposed that definite personality attributes are more accordant with the spiritual intelligence characteristics than others. In an 


\section{J. Social Sci., 6 (3): 429-438, 2010}

effort to examine various personality theories, encircling the McCrae and Costa (2002) Big five personality theory, the characteristics of emotional stability, agreeableness, agreeableness and openness seem to be those characteristics most commonly used for expressing the spiritual intelligence. These attributes are accordant with the stable, kind, responsible, openminded and creative natures correlated with a high level of spiritual intelligence development.

From different point of view, Piedmont (1999) has posited that spirituality may exemplify a separate attribute of personality. MacHovec (2002) has likewise contended that spiritual intelligence may be regarded as a personality attribute that differs in strength and the nature of expressing which among individuals, much like any other personality characteristic. Its uniqueness is stated to be characterized by its distinctive subjective experience and a broad transcending quality that is demonstrated in a cognitive and effective manner and that is contributory to creation and self-expansion (MacHovec, 2002). This kind of subjective experience, linked with spiritual intelligence, may be realized as feeling of enlightenment, wonder, inspiration, or boosted awareness (MacHovec, 2002). This opinion may be viewed as an outgrowth of James (1902; 1961) and later, of Allport (1950) postulates, that religiousness ought to be thought of as a prospect of the structure of the individual's personality, because it shows a selected, combined regime for leading the life of the individual and putting it in context. Yet, the concept of spiritual intelligence as a definite personality structure has not been properly improved yet, neither improved, nor even theoretically. Flowing in line with Piedmont (1999) thought, the spiritual intelligence may present a combination of personality factors, e.g., interest in, expression of and access to spiritual information) and intelligence-related information processing (aptness and skills for effective processing of this type of information). The very concept can be expanded to additional, not any less solid individual strengths and capabilities too, like the natural capability for parenting, treating, or expressing artistically. It may be claimed that such intrinsic propensities, once present, furnish specific paths for expressing spiritual intelligence and that developing spiritual intelligence may foster these competencies and strengths.

In addition, almost in the outset of this chapter, a discussion was provided on that spiritual intelligence functions in combining itself both with the EQ and the IQ and on that it possesses a capability of changing their interaction results, therefore making possible the personal development and change. It additionally allocates the employment of other intelligence aspects in a context that is deeper and wider (Deslauriers, 2000). If the spiritual intelligence is interrelated with other types of intelligence in this way, then differences between individuals in the EQ and IQ levels affect enacting and utilizing the spiritual intelligence (Zohar and Marshall, 2000a). As an illustration, intelligence facets expressed by measurements of the IQ are necessary to comprehend events in the individual's environment and to identify troubles (Sternberg, 1997) on which spiritual resources and capacities may be practiced. In the sense of EQ, the extent of emotional competence and control of an individual in assessing emotion of others potentially influence his or her revealing of feelings of association with others, selfawareness and the capability to exhibit righteous behaviors like compassion, humility, forgiveness and gratitude (Emmons, 2000b; Sinetar, 2002).

Spiritual intelligence has been perceived in this study as mainly a positive component. There are advantages for being spiritually intelligent, just as there are merits for any other form of intelligence. However, can one have too much of a good thing? Is there a down side to being spiritually intelligent? Is there an optimal amount of spiritual intelligence? Or to cite the same question in different words, does it make sense to name someone as "spiritually unintelligent?" These are major and significant questions to consider. There is a dark side to the religious life which is beyond the question. The construct of spiritual intelligence might be able to shed light on the possible harmfulness of religious beliefs or spiritually oriented lifestyles. Just like many other skills, spiritual intelligence may be put to cruel as well as to noble goals. It is not inevitably a positive feature.

It is clear that a person could overestimate his or her spiritual intellect while neglecting other aspects of functioning. Becoming spiritual might be dangerous to the extent that the person will be unable to act properly in the world, for example, being so "otherworldly focused" that the individual is not able to operate perfectly with the concrete requests of routine life. A spiritually intelligent person is able to match earthly and heavenly spirituality. Problems in psychological or interpersonal functioning may derive from an inequality in the formation of the special constructs, or with an exclusive concern with some constructs to the overlook of others. For instance, there may be some individuals who have highly developed capabilities for transcendence or mystical experiences; however, they have lived a passive life in which they have been detached from this world. In contrast, there are some disadvantages for being too easily forgiving, too grateful, too humble, or too self-controlled. Extremes in 
each of the components is likely to become maladaptive, specifically when integrated with emotional instability, basic character mistakes, or an inability to lead one's spiritual intelligence in a noble direction.

Briefly, it can be said the spiritual intelligence concept and its integration with the recent conception of individual represent a novel psychologic personality and intelligence model (Davidson, 2002). In specific, spiritual intelligence seems not to entirely include reasoning or cognition of the abstract type. The huge, incognitive construct of the spiritual intelligence contains capabilities for awareness to instinctive messages and to the interior voice of the individual, for instilling the activities and relationships of the individual with sanctity sense and for reaching consciousness superior or spiritual statuses. Furthermore, a number of inter-, as well as, intrapersonal skills ideally linked with emotional intelligence are appropriate for employment by the spiritual one as well. These skills, however, are reflexed by Carl Rogers' therapeutic notion of unconditional positive consideration of the others (MacHovec, 2002). Yet, these spirituality experiential scales ought not to incapacitate the spiritual intelligence as legitimate one; rather, they should extend our comprehension about intelligence. Spiritual intelligence provides general basis for individuals to be able to consider their quest for goals and meaning in their lives and to move toward the goals which are personally meaningful. It aids individuals to direct their attentions to the 'bigger picture' and to focus, consciously, their activities within a broader context. Although spiritual intelligence does not necessarily have to include belief of the individual in a higher power, it surely directs people to the superior scope of the experience they develop and to the spiritual dimension of each one's self. Spiritual intelligence is often argued to be particularly helpful in considering and solving the issues which are associated with the value and meaning and applied for debating over experiential obsessions.

Another feature of spiritual intelligence is development of self-knowledge and personal awareness. In like manner, an individual may take spiritual intelligence to produce extra depth and passion in the daily actions. This, however, may be achieved through employing spiritual intelligence in directing and controlling the individual's own behavior and interplay in order for the subjective conception of incidents and experiences to be reinterpreted and for personal, meaningful targets to be reconsidered. Similar potentialities and capabilities forming the spiritual intelligence of the individual may additionally be used for practical solving of barriers and/or problems with which a person is faced in daily life. Hence, it can be concluded that spiritual intelligence is quite of use past definite existential or even spiritual settings. Anyhow, care ought to be practiced to make sure that the spiritual skills or resources will not be replaced or misapplied for extra context-specific intelligence or for problemoriented strategic plans once they are required.

A dynamic infrastructure for spiritual intelligence has been suggested, for it is believed that spiritual intelligence is an innate potentiality which is related to the global experience of spirituality. Anyhow, findings of the research available which focus on the rudimentary spiritual intelligence physiologic mechanisms are not certain and hence should be translated with prudence. There are some controversial or over simplified definitions provided by many findings for the physiological processes which are claimed to be engaged in the spiritual intelligence functioning. Irrespective if specific physiologic structures are, or are not, proved to be playing a role in the spiritual intelligence, it may be cultivated and distilled throughout the scope of life. Numerous suggestions have been set forth for development of the spiritual intelligence of the individual. These include such recommendations as deepening the level of selfawareness; controlling a speculative mentality; learning from occult experiences; recognizing individual's intuition; raising the 'why' questions and widening views and staying extroverted to experience. There are several general characteristics to recognize a highly cultivated spiritual intelligence. They include capability to inspire others, deep self awareness, flexibility, compassion and openness.

As mentioned earlier, capacities and skills which are linked with spiritual intelligence may vary from individual to individual in light of variations in personality features, spiritual tendencies, religious backgrounds and the religious practices and activities they follow. Since wisdom is regarded as one facet of spiritual intelligence, then the scope of clear intelligence and the pragmatic knowledge of a person could additionally affect his/her application of spiritual intelligence, especially when taking decisions and resolving problems. Therefore, spiritual intelligence can, in part, indicate combination of intelligenceassociated processing and personality parameters. Additionally, differences may exist among special groups. With regard to the traditional Christianity varying orientations and the New Age, or individualistic (personalistic) spirituality, which the scientific literature explains, variations might be observed in the kinds of spiritual capabilities, resources 
and activities. And members belonging to such groups tend to pull in. When spirituality is considered as facet of intelligence, it widens conception of spirituality of psychologists and associates spirituality with logical cognitive processes like resolving problems and achieving goals. The spiritual intelligence build up, in addition, attracts attention to the adaptive, functional and positive spirituality characteristics. Besides, it challenges the spirituality notions which describing it as non-rational, over-emotional, over credulously based and of low actual value (Emmons, 2000b). Anyhow, conflicts have been raised on tentative hazards associated with the abuse and improper application of and over-dependence on experience spiritual scope.

There are also some questions raised when reflecting on the foundation of spiritual intelligence and these whether or not aid can be encountered in the spiritual intelligence universality and whether or not there exists continuity, from low to high, in spiritual intelligence, as it exists for other forms of intelligence (Noble, 2000).

\section{CONCLUSION}

Reviewing the literature showed that, spiritual intelligence can improve with training. Adolescence is an important period for spiritual intelligence training and gratitude as a subscale in SQ has ability to increase that fortunately, many individuals have described specific exercises to promote gratitude. As a sort of intelligence, spirituality extends the psychologist's conception of spirituality and allows its association with rational cognitive processes like goal achievement and problem resolution. The spiritual intelligence provides a general basis for the individual to be able to consider his seeking for goals and meaning in life and to move in the direction of the aims which are personally meaningful. It aids the individual in directing his/her concerns to the wider image and in focusing, consciously, his/her activities in a context that is wider.

\section{REFERENCES}

Allport, G.W., 1950. The Individual and his Religion: A Psychological Interpretation. 1st Edn., Macmillan, New York, pp: 147.

Amram, Y., 2007. The seven dimensions of spiritual intelligence: An ecumenical grounded theory. Proceeding of the 115th Annual Conference of the American Psychological Association, Aug. 17-20, SI_APA, San Francisco, CA., pp: 1-9. http://www.yosiamram.net/docs/7_Dimensions_of _SI_APA_confr_paper_Yosi_Amram.pdf
Avenevoli, S. and L. Steinberg, 2001. The continuity of depression across the adolescent transition. Adv. Child Dev. Behav., 28: 139-173. PMID: 11605363

Bowell, R.A., 2005. The 7 Steps of Spiritual Intelligence: The Practical Pursuit of Purpose, Success and Happiness. 1st Edn., Nicholes Brealey Publishing, UK., pp: 250.

Costello, E.J., A. Erkanli, J.A. Fairbank and A. Angold, 2002. The prevalence of potentially traumatic events in childhood and adolescence. J. Trauma. Stress, 15: 99-112. PMID: 12013070

Davidson, R.J., 2002. Anxiety and affective style: Role of prefrontal cortex and amygdala. Biol. Psychiatry, 51: 68-80. PMID: 11801232

Deslauriers, D., 2000. Dreamwork in the light of emotional and spiritual intelligence. Adv. Dev., 9: 105-122.

Edwards, A.C., 2003. Response to the spiritual intelligence debate: Are some conceptual distinctions needed here? Int. J. Psychol. Relig., 13: 49-52. DOI: 10.1207/S15327582IJPR1301_05

Elmer, L.D., D.A. MacDonald and H.L. Friedman, 2003. Transpersonal psychology, physical health and mental health: Theory, research and practice. Hum. Psychol., 31: 159-181. DOI: 10.1080/08873267.2003.9986929

Emmons, R.A., 2000a. Is spirituality an intelligence? Motivation, Cognition and the Psychology of Ultimate Concern. Int. J. Psychol. Relig., 10: 3-26. DOI: 10.1207/S15327582IJPR1001_2

Emmons, R.A., 2000b. Spirituality and intelligence: Problems and prospects. Int. J. Psychol. Relig., 10: 57-64. DOI: 10.1207/S15327582IJPR1001_6

Emmons, R.A., 2003. The Psychology of Ultimate Concerns: Motivation and Spirituality in Personality. 1st Edn., The Guilford Press, New York, pp: 230.

Erikson, E.H., 1950. Childhood and Society. 1st Edn., Norton, New York, pp: 397.

Erikson, E.H., 1959. Identity and the Life Cycle: Selected Papers, (Psychological Issues). 1st Edn., International Universities Press, New York, pp: 171.

Erikson, E.H., 1968. Identity, Youth and Crisis. 1st Edn., Norton, New York, pp: 230.

Erikson, E.H., 1969. Gandhi's Truth. 1st Edn., W.W. Norton, New York, pp: 316.

George, L.K., D.B. Larson, H.G. Koenig and M.E. McCullough, 2000. Spirituality and health: What we know and what we need to know. J. Soc. Clin. Psychol., 19: 102-116. http://www.psy.miami.edu/faculty/mmccullough/P apers/spirituality $\% 20$ and $\% 20$ health_george_larson _et\%20al._JSCP.pdf 
Goleman, D., 1995. Emotional Intelligence. 1st Edn., Bantnam, New York, pp: 368.

Hankin, B.L. and L.Y. Abramson, 2001. Development of gender differences in depression: An elaborated cognitive vulnerability-transactional stress theory. Psychol. Bull., 127: 773-796. PMID: 11726071

James, W., 1902. The Varieties of Religious Experience: A Study in Human Nature. 2nd Edn., Routledge UK., pp: 415.

James, W., 1961. The Varieties of Religious Experience. 1st Edn., Collier Books, New York, pp: 313.

Kass, J.D., R. Friedman, J. Leserman, P.C. Zuttermeister and H. Benson, 1991. Health outcomes and a newindex of spiritual experience. J. Sci. Study Relig., 30: 203-211. http://www.jstor.org/stable/1387214

Levin, S.M., 1997. Put the shoulder to the wheel: A new biomechanical model for the shoulder girdle. Biomed. Sci. Instrum., 33: 412-417. PMID: 9731395

MacDonald, D.A. and D. Holland, 2003. Spirituality and the MMPI-2. J. Clin. Psychol., 59: 399-410. PMID: 12652633

MacHovec, F., 2002. Spiritual Intelligence: Behavioral Sciences and the Humanities. 1st Edn., Edwin Mullen Press Ltd., Lewiston, NY., pp: 291.

Masten, A.S., 1988. Towards A Developmental Psychopathology of Early Adolescence. In: Early Adolescent Transitions, Levine, M.D. and E.R. McAnarney (Eds.). Health, Lexington, MA., pp: 261-278.

Mayer, J.D., 2000. Spiritual intelligence-or spiritual consciousness? Int. J. Psychol. Relig., 10: 47-56. DOI: 10.1207/S15327582IJPR1001_5

McCrae, R.R. and P.T. Costa, Jr., 2002. Personality in Adulthood: A Five-Factor Theory Perspective. 2nd Edn., The Guilford Press, New York, pp: 268.

Moffitt, T.E., A. Caspi, M. Rutter and P.A. Silva, 2001. Sex Differences in Antisocial Behavior: Conduct Disorder, Delinquency and Violence in the Dunedin Longitudinal Study. 1st Edn., Cambridge University Press, Cambridge, UK., pp: 300.

Morison, P. and A.S. Masten, 1991. Peer reputation in middle childhood as a predictor of adaptation in adolescence: a seven-year follow-up. Child Dev., 62: 991-1007. PMID: 1756670
Nasel, D., 2004. Spiritual orientation in relation to spiritual intelligence: A new consideration of traditional Christianity and new age/individualistic spirituality. Ph.D. Thesis, University of South Australia.

http://arrow.unisa.edu.au:8080/vital/access/manage r/Repository/unisa:24948

Noble, E.P., 2000. The $\mathrm{DRD}_{2}$ gene in psychiatric and neurological disorders and its phenotypes. Pharmacogenomics, 1: $\quad 309-333$. PMID: 11256581

Piedmont, R.L., 1999. Does spirituality represent the sixth factor of personality: Spiritual transcendence and the Five-Factor model? J. Person., 67: 9851013. DOI: $10.1111 / 1467-6494.00080$

Seybold, K.S. and P.C. Hill, 2001. The role of religion and spirituality in mental and physical health. Curr. Direct. Psychol. Sci., 10: 21-24. http://www.jstor.org/stable/20182684

Sinetar, M., 2002. Spiritual Intelligence. What We Can Learn from the Early Awakening Child. 1st Edn., Orbis Books, Maryknoll, NY., pp: 224.

Sisk, D.A. and E.P. Torrance, 2001. Spiritual Intelligence: Developing Higher Consciousness. 1st Edn., Creative Education Foundation, Buffalo, NY., pp: 196.

Sternberg, R.J., 1977. Component processes in analogical reasoning. Psychol. Rev., 84: 353-378.

Trott, D., 1996. Spiritual well-being of workers: An exploratory study of spirituality in the workplace. University of Texas.

Vaughan, D., 2002. Media launch. Contexts, 1: 68-69. DOI: $10.1525 /$ ctx.2002.1.2.68

Veach, T. and J. Chappel, 1992. Measuring spiritual health: A preliminary study. Subst. Abuse, 13: 139-147.

Walsh, R., 2000. Essential Spirituality: The 7 Central Practices. 1st Edn., Wiley, New York, pp: 320.

Wolman, R.N., 2001. Thinking with Your Soul: Spiritual Intelligence and Why it Matters. 1st Edn., Harmony Books, New York, pp: 289.

Zohar, D. and I. Marshall, 2000a. SQ-Spiritual Intelligence: The Ultimate Intelligence. 1st Edn., Bloomsbury Publishing Ltd., London, pp: 324.

Zohar, D. and I. Marshall, 2000b. SQ: Connecting with Our Spiritual Intelligence. 1st Edn., Bloomsbury, USA., pp: 288. 